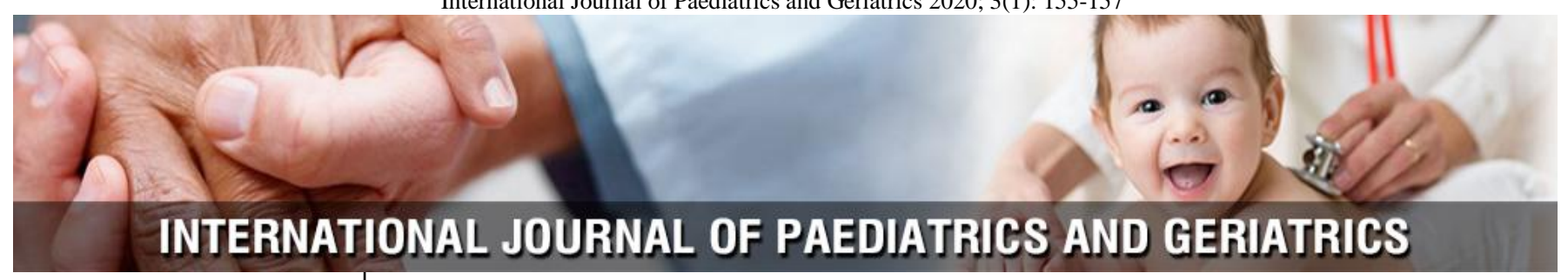

P-ISSN: 2664-3685

E-ISSN: $2664-3693$

www.paediatricjournal.com

IJPG 2020; 3(1): 155-157

Received: 20-12-2019

Accepted: 05-01-2020

Karavadra B

Norfolk \& Norwich University

Hospital, Colney Lane,

Norwich, NR4 7UY, England

Gunawardena I

Norfolk \& Norwich University

Hospital, Colney Lane,

Norwich, NR4 7UY, England

\section{Memory problems and weight loss: A case report}

\section{Karavadra B and Gunawardena I}

DOI: https://doi.org/10.33545/26643685.2020.v3.i1c.74

\section{Abstract}

This interesting case report illustrates a paraneoplastic syndrome presenting as dementia. A 75-year-old Malaysian lady with a 45-pack year smoking history presented with unintentional weight loss of three stone in three months with generalised "aches and pains" and short-term memory problems. Her inflammatory markers were raised, liver function tests were deranged, and her thyroid stimulating hormone was low. Cerebrospinal fluid examination revealed a mild increase in protein. On the Addenbrooke's Cognitive Scale her score was 39/100 and she also had clinical features to suggest mild depression. A Computed Tomography of the thorax showed a $34 \mathrm{~mm}$ mass anterior to the trachea and an enlarged right para-tracheal lymph node. Subsequent endo-bronchial ultrasound biopsy confirmed metastatic small-cell lung cancer. She had positive autoantibodies for anti-Hu and anti-Sox 1; indicating a paraneoplastic syndrome or limbic encephalitis. Paraneoplastic syndromes are rare and difficult to diagnose. In this case, the paraneoplastic manifestations mimicked a dementia illness.

Keywords: paraneoplastic syndrome, dementia, cancer

\section{Introduction}

Paraneoplastic syndromes are rare and affect less than one person for every 10,000 people with malignancy. Patients represent the remote effects of the malignancy. Neuropsychiatric symptoms may appear before the clinical presentation of the primary tumour. The paraneoplastic syndromes are due to autoimmune processes where antibodies are directed against onco-neural antigens and it is these antibodies that can be detected in the serum to aid clinical diagnosis. Importantly, only less than $50 \%$ of patients with a paraneoplastic syndrome will have detectable antibodies in their serum. In approximately $20 \%$ of cases, the underlying malignancy is not found [6]. Epidemiologically, the most common type of paraneoplastic syndrome is Lambert-Eaton myasthenic syndrome and is associated with small cell lung cancer ${ }^{[6]}$. A number of cases of paraneoplastic syndrome associated with small cell lung cancer have been described ${ }^{[1,2,3]}$. All the cases describe the complexities involved in not only diagnosing a paraneoplastic syndrome, but also managing the patient ${ }^{[4]}$. Paraneoplastic syndromes can present even before the actual underlying tumour presents clinically ${ }^{[7]}$. Patients with cancer are living longer and therefore it is important to appreciate that the prevalence of paraneoplastic syndromes may also increase as a result ${ }^{[7]}$.

\section{Case presentation}

A seventy five year old Malaysian lady with a 45 pack year history of smoking presented to her General Practitioner with unintentional weight loss of three stone in three months. A collateral history obtained from her family revealed she had declined over an eight month period with short term memory loss, low mood, and loss of appetite, generalised joint aches and lethargy. She had no weakness, incontinence, rashes, history of falls or recent head trauma or seizure activity. She had a past medical history of gastro oesophageal reflux disease and bilateral breast implantation. She had no known allergies and only took daily lansoprazole. There was no significant family history. She lived alone, walked independently and managed her activities of daily living without assistance. She rarely consumed alcohol and did not use any recreational drugs. She was a housewife in Malaysia and since her divorce had been resident in the UK for 2 years. Prior to her illness she enjoyed an active social life.

On examination, she was confused, restless and agitated but orientated in time place and person with no fluctuation in her symptoms. Abbreviated mental test score on admission was 3/10 (for monarch, two person recognition and time). Her Addenbrookes Cognitive Scale

\section{Karavadra $B$}

Norfolk \& Norwich University

Hospital, Colney Lane,

Norwich, NR4 7UY, England 
score was 39/100. In addition, she had oral candida but no evidence of clubbing or lymphadenopathy. Cardiorespiratory, abdominal and neurological examinations were unremarkable.

Blood tests on admission showed a C-reactive protein of 128, leucocytosis at 13.8, mean cell volume 77 , haemoglobin $135 \mathrm{~g} / \mathrm{L}$ albumin 31 and thyroid stimulating hormone of 0.26. Deranged liver function tests showed alanine transferase of 88 , gamma glutamyltransferase of 72 and total bilirubin at 28. Her renal function was unremarkable apart from creatinine at 47. Serology for Human Immunodeficiency virus, herpes simplex, varicella zoster and enterovirus were negative. Electrocardiogram, Chest x-ray, abdominal radiograph, Computed Tomography and Magnetic Resonance Imaging of the brain were unremarkable and non-diagnostic.

An autoimmune screen comprising of an antinuclear antigen screen, autoantibody screen (including AMA, ASMA,anti liver, anti kidney, anti gastric and anti reticulin R1), rheumatoid factor and anti amphiphysin antibody was also negative.

Computed Tomography of the thorax showed a $34 \mathrm{~mm}$ mass anterior to the trachea. Endobronchial ultrasound biopsy of this mass demonstrated metastatic small cell cancer. In addition, fluorescence patterns on the cerebellum showed positive nuclear staining of the purkinje cells coupled with a positive serum result for anti-Hu and weak positive result for anti-Sox-1 antibody. These findings were consistent with a paraneoplastic syndrome. The patient was commenced on palliative radiotherapy. She was discharged home, but showed a poor response to treatment and sadly died a few months later.

Figures 1-4 show a summary of the serum blood results.

\begin{tabular}{|c|c|}
\hline WCC & $13.8 \uparrow$ \\
\hline CRP & $128 \uparrow$ \\
\hline MCV & $77 \downarrow$ \\
\hline Hb & $135 \mathrm{~g} / \mathrm{L}$ \\
\hline Albumin & $31 \downarrow$ \\
\hline ALP & 111 \\
\hline ALT & $84 \uparrow$ \\
\hline GGT & $72 \uparrow$ \\
\hline Total bilirubin & $28 \uparrow$ \\
\hline Ca2+ & 2.57 \\
\hline Phosphate & 0.95 \\
\hline eGFR & 79 \\
\hline Na & 134 \\
\hline K & 4.1 \\
\hline Urea & 4.9 \\
\hline Creatinine & $47 \downarrow$ \\
\hline
\end{tabular}

Fig 1: Blood results on admission; Table detailing bloods on admission

\begin{tabular}{|c|c|}
\hline HIV serology & $\rightarrow$ Negative \\
\hline Herpes simplex virus 1\&2 & $\rightarrow$ Negative \\
\hline Varicella zoster DNA & $\rightarrow$ Negative \\
\hline Enterovirus RNA & $\rightarrow$ Negative \\
\hline
\end{tabular}

Fig 2: Serology; Table detailing viral serology

\begin{tabular}{|c|c|}
\hline ANA screen (dsDNA, Ro, La, Centromere, scl-70) & Negative \\
\hline Rh factor & Negative \\
\hline Autoantibody screen (AMA, ASMA, Anti liver, kindey microsomal Abs, anti gastric parietal cell Abs, anti reticulin R1) & Negative \\
\hline Anti amphiphysin Ab & Negative \\
\hline
\end{tabular}

Fig 3: Auto-immune screen; Table detailing the blood results for an auto-immune screen.

\begin{tabular}{|c|c|}
\hline Fluorescence patterns on cerebellum showed +'ve nuclear staining of the purkinje cells & \multicolumn{1}{|c|}{} \\
\hline Neuronal Ab tests: & $\begin{array}{c}\text { Associated with encephalomyelitis, sensory } \\
\text { neuropathy \& cerebellar ataxia }\end{array}$ \\
\hline Anti Hu- POSITIVE & \\
\hline Anti Yo- NEG & \\
\hline Anti Ri- NEG & \\
\hline Anti Ma1- NEG & Anti Hu \& Anti Sox $\rightarrow$ SMALL CELL LUNG \\
Anti Ma2- NEG & CANCER \& neuroblastoma \\
\hline Anti Amphiphysin- NEG &
\end{tabular}

Fig 4: Auto-antibody screen; Table detailing the results for an auto-antibody screen.

\section{Conclusion}

This case highlights the importance of ruling out organic illness in a patient presenting with nonspecific symptoms which may be attributed to a psychiatric illness and the need for repeated clinical review and investigation in patients where initial findings are unremarkable.

This case has highlighted the importance of multidisciplinary team working and the benefits this can have in reaching a diagnosis, but also improving overall outcomes for the patient.

It is important to be mindful about the wide differential diagnosis in patients presenting with non-specific problems. In old age, malignancy as a differential diagnosis should be at the forefront. Whilst dementia is a common illness in the older population, other causes that may mimic the condition need to be explored. This will undoubtedly help to manage symptoms better, but also help with prognosis; particularly in cases of malignancy.

\section{Competing interests}

The author(s) declare that they have no competing interests.

\section{Authors' contributions}

$\mathrm{BK}$ and IG were part of the medical team looking after this patient. BK was the junior doctor; he performed a literature search and wrote the basis of this case report. BK also sent the consent form to the next of kin. IG was the consultant in charge of this case and he also contributed to this case by editing and overseeing the report as a whole. 


\section{References}

1. Porte H, Rousselot C, Taieb S, Outteryck O, Dansin E. Anti-Hu antibody syndrome: diagnostic and therapeutic difficulties. Sep. Case Reports. 2013; 30(7):563-6.

2. Prouzova Z, Brychtova S, Klinicka Onkologie. Paraneoplastic neurological syndrome in 64-year-old patient in association with a small cell lung carcinoma. Czech. 2012; 25(6):471-5.

3. Moskovitz DN, Robb KV. Small cell lung cancer with positive anti-Hu antibodies presenting as gastroparesis. Canadian Journal of Gastroenterology. 2002; 16(3):171-4.

4. Wakatsuki M, Matsuo K, Kayatani H, Fujiwara K, Yonei T, Sato T et al. A case of small cell lung cancer that presented with paraneoplastic syndrome. 2011; 49(7):517-22.

5. Dalmau J, Rosenfeld M. Paraneoplastic syndromes of the CNS. The Lancet Neurology. 7(4):327-340.

6. Rees JH. Paraneoplastic syndromes: when to suspect, how to confirm, and how to manage. J Neurol Neurosurg Psychiatry. 2004; 75:43-50

7. Pelosof L, Gerber D. Paraneoplastic syndromes: An approach to diagnosis and treatment. 2010; 85(9):838854. 